\title{
Ionospheric foF2 morphology and response of F2 layer height over Jicamarca during different solar epochs and comparison with IRI-2012 model
}

\author{
B O Adebesin ${ }^{1, *}$, B J Adekoya ${ }^{2}, \mathrm{~S} \mathrm{O} \mathrm{Ikubanni}^{1}, \mathrm{~S} \mathrm{~J} \mathrm{Adebiyi}^{1}$, \\ O A Adebesin ${ }^{3}$, B W JoshuA ${ }^{4}$ and K O OlOnAdE ${ }^{5}$ \\ ${ }^{1}$ Department of Industrial Physics, Landmark University, P.M.B. 1001, Omu-Aran, Kwara State, Nigeria. \\ ${ }^{2}$ Department of Physics, Olabisi Onabanjo University, Ago-Iwoye, Ogun State, Nigeria. \\ ${ }^{3}$ MTN Nigeria Communications Limited, 5th Floor, Golden Plaza Building, Falomo, Ikoyi, Lagos Nigeria. \\ ${ }^{4}$ Department of Physics, Kebbi State University of Science and Technology, P.M.B 1144 , \\ Aliero, Kebbi State, Nigeria. \\ ${ }^{5}$ School of Science and Technology, Moshood Abiola Polytechnic, P.M.B. 2210, Ojere, \\ Abeokuta, Ogun State, Nigeria. \\ ${ }^{*}$ Corresponding author.e-mail: f_adebesin@yahoo.co.uk femiadebesin@gmail.com
}

Diurnal, seasonal and annual foF2 variability and the response of the F2-layer height over Jicamarca $\left(11.9^{\circ} \mathrm{S}, 76.8^{\circ} \mathrm{W}, 1^{\circ} \mathrm{N}\right.$ dip) during periods of low (LSA), moderate (MSA) and high (HSA) solar activities was investigated. The relative standard deviation $\left(V_{R}\right)$ was used for the analysis. The F2-layer critical frequency pre-noon peak increases by a factor of 2 more than the post-noon peak as the solar activity increases. The variability coefficient $\left(V_{R}\right)$ is lowest during the day $(7-16 \%)$ for the three solar epochs; increases during nighttime $(20-26 \%, 14-26 \%$, and $10-20 \%$, respectively for the LSA, MSA and HSA years); and attained highest magnitude during sunrise $(21-27 \%, 24-27 \%$, and $19-30 \%$, respectively in similar order). Two major peaks were observed in $V_{R}$ - the pre-sunrise peak, which is higher, and the post-sunset peak. Generally, the variability increases as the solar activity decreases. Annually, $V_{R}$ peaks within $23-24 \%, 19-24 \%$ and $15-24 \%$ for the LSA, MSA, and HSA periods, respectively. The ionospheric F2-layer height rises to the higher level with increasing solar activity. The foF2 comparison results revealed that Jicamarca is well represented on the IRI-2012 model, with an improvement on the URSI option. The importance of vertical plasma drift and photochemistry in the F2-layer was emphasized.

\section{Introduction}

The F2-region is the most important region in the ionosphere for long distance high frequency communication because of its thickness and minimal attenuation for probing radio waves. Variations in the critical frequency (foF2), however, provide hints on the happenings within the F2-layer as a whole. Observations show that foF 2 rises after sunrise, the rise being more frequent at lower latitude. Maximum is reached in the early afternoon, and there is a rapid fall shortly after sunset. foF 2 is generally highest in the neighbourhood of the equator. The variation of foF 2 along a line of fixed time in the afternoon, which depends, for a station, on the season and epoch of the solar cycle is known as the equatorial anomaly. For a better understanding of the foF 2 spread, several works

Keywords. F2-layer; critical frequency; solar activity; relative standard deviation; post-sunset; plasma drift. 
have been carried out. Fejer (1997), Risbeth and Mendillo (2001), Batista and Abdu (2004), Bilitza et al. (2004), Zhang et al. (2004), Gordienko et al. (2005), Oladipo et al. (2008), Atac et al. (2009) and Adebesin (2012), had investigated the depiction of foF2 ionospheric variability during various seasons, time of the day, solar cycles, and latitudes. Zhang and Holt (2008) typified electron density variability and plasma temperatures at midlatitudes. Oladipo et al. (2009) investigated the electron density distribution at fixed heights by making use of the Gaussian distribution test. Jin et al. (2008) and Lilensten and Blelly (2002), on the other hand, used GPS observations to study foF2 variability pattern at different latitudes. However, according to Adeniyi et al. (2007), studies on variability vary from those that analyse specific parameters on a large geographical area, to those that are limited to a few or one station.

The present work investigates the diurnal, seasonal, and annual foF2 variability over the single equatorial station of Jicamarca (lat. $11.9^{\circ} \mathrm{S}$, long. $76.8^{\circ} \mathrm{W}, 1^{\circ} \mathrm{N}$ dip) in the South America sector during different solar activity periods using the relative standard deviation $\left(V_{R}\right)$, as well as the response of the F2-layer height. Note that other parameters besides the mean $(\mu)$ and standard deviation $(\sigma)$ had been used in some previous works to illustrate the foF2 variability (e.g., Kouris and Fotiadis 2002). Such works have used the upper/lower quartiles or deciles to represent the data scatter. These latter parameters have the advantage of being interpreted easily in terms of probability (in the first half of the data) but ignore the other half. However, the relative standard deviation provides a better gauge for unfolding the average deviation from the monthly mean, though it is difficult to interpret in terms of probability.

\section{Data and method of analysis}

The data for this study are the F2-layer critical frequency (foF2) and height of the peak electron density (hmF2) hourly values from Jicamarca (lat. $11.9^{\circ} \mathrm{S}$, long. $76.8^{\circ} \mathrm{W}, 1^{\circ} \mathrm{N}$ dip). The datasets obtained from the Space Physics Interactive data Resource (SPIDR) website (http://spidr.ngdc.noaa. gov) was automatically scaled with an accuracy of $\pm 0.3 \mathrm{MHz}$ at $95 \%$ confidence level, and cover years of low, moderate, and high solar activities. The foF2 data from the SPIDR was further validated using the most recent data model from the International Reference Ionosphere (IRI-2012 model), as will be seen later in this work. In standard practice, ionospheric variations are characterized in summer, winter, or equinoctial periods (e.g., Iheonu and Oyekola 2006; Chaitanya et al. 2012).
For this reason, data for the months of March and September represent the equinoctial periods. Because Jicamarca falls in the Southern Hemisphere, data for the months of June are used for winter season, while December data falls in the summer season. We have employed two years data for each solar activity period. For instance, we have made use of 2009 and 2010 data for low solar activity (LSA) period, 2004 and 2005 data for moderate solar activity (MSA), and 2001 and 2002 data for the high solar activity (HSA) period. This was done so that we can build a better statistical sample for representing each level of solar activity. Some earlier works (e.g., Radicella and Adeniyi 1999; Anderson et al. 2006; Oladipo et al. 2009) adopted the idea of using representative months for each of the seasons and their results are reasonable and well documented. Table 1 lists the years selected with months and their respective annual solar flux values. The solar flux at $10.7 \mathrm{~cm}\left(\mathrm{~F}_{10.7}\right)$ is a proxy index for characterizing solar activity and is obtained from NSSDC's OMNI database website (http://nssdc.gsfc.nasa.gov/omniweb).

Following the example of Bilitza et al. (2004 and the references therein), as well as Rishbeth and Mendillo (2001), we have employed the monthly mean $(\mu)$ and standard deviation $(\sigma)$ to estimate the monthly variability, assuming that the variations represent real changes in electron density and not just a redistribution of the existing plasma. The standard deviation $(\sigma)$ is the usual way of quantifying precision, and hence is a measure of how precise the average is; that is, how well the individual datasets agree with each other. Standard deviation is given mathematically as:

$$
\sigma=\sqrt{\frac{\sum_{i=1}^{N}\left(x_{i}-\mu\right)^{2}}{N-1}}
$$

where $(\mu)$ is the arithmetic mean taken as the data average, $x_{i}$ is the individual data point, $N$ is the number of data points, and quantity $\left(x_{i}-\mu\right)$ is the deviation of each data point from the average. On the other hand, the relative standard deviation is the absolute value of the coefficient of variation. It is often expressed as a percentage. A lower percentage indicates a lower variability in the dataset. Equally, a higher percentage indicates the dataset is more varied. The relative standard deviation $V_{R}$ gives the precision as a percentage of the mean (average). Data that are more precise yield a smaller relative standard deviation. The ionospheric foF 2 relative standard deviation $V_{R}$ used in this study is given by:

$$
V_{R}(\%)=\left(\frac{\sigma}{\mu}\right) \cdot 100
$$


Table 1. Data-years used with corresponding average solar flux values.

\begin{tabular}{llll}
\hline Solar period & \multicolumn{1}{c}{ Equinox } & Winter & Summer \\
\hline Low solar activity years & & & \\
$2010\left(\mathrm{~F}_{10.7}=80 \mathrm{sfu}\right)$ & March and September/October & June & December \\
$2009\left(\mathrm{~F}_{10.7}=71 \mathrm{sfu}\right)$ & March and September & June & December \\
Moderate solar activity years & & & \\
$2004\left(\mathrm{~F}_{10.7}=106 \mathrm{sfu}\right)$ & March and September & June & December \\
$2005\left(\mathrm{~F}_{10.7}=98 \mathrm{sfu}\right)$ & March and September & June & December \\
High solar activity years & & & \\
$2001\left(\mathrm{~F}_{10.7}=185 \mathrm{sfu}\right)$ & $* *$ and September/October & June & December \\
$2002\left(\mathrm{~F}_{10.7}=176 \mathrm{sfu}\right)$ & March and September & June & December \\
\hline
\end{tabular}

**Data not available for March 2001. $1 \mathrm{sfu}=10^{-22} \mathrm{Wm}^{-2} \mathrm{~Hz}^{-1}$.

Oladipo et al. (2008) and Akala et al. (2011) had made use of similar variability index in investigating the ionospheric variability at some other ionospheric stations.

It is widely known that many natural phenomena/ observations follow the normal or Gaussian distribution. The use of relative standard deviation as our variability index $\left(V_{R}\right)$ therefore is because the foF2 data used is nearly a perfect Gaussian distribution. This was achieved by applying the Gaussian distribution condition of equation (3), which states that about $2 / 3$ or 0.6826 of all cases (of an observation) fall within one standard deviation of the mean.

$$
P\left(\mu-\sigma \leq x_{i} \leq \mu+\sigma\right)=0.6826
$$

where $\mu, \sigma$, and $x_{i}$ take their usual meaning, and $P$ is the probability of occurrence. For the foF2 data used in this work, the probability that the hourly set of foF 2 fall within the range \pm of a standard deviation $(\sigma)$ centered on the mean $(\mu)$ is $\geq 0.6826$ is about $73 \%$, irrespective of time of the day, season or solar activity period. This percentage is near Gaussian distribution; hence, the use of $V_{R}$ has been justified. Adeniyi et al. (2007) had performed similar test on the foF2 data obtained from another equatorial station in the African sector (Ouagadougou, Burkina Faso, lat. $12.4^{\circ} \mathrm{N}$, long. $1.5^{\circ} \mathrm{W}$ ) for 1985,1990 and 1993 , representing years of low, high and moderate solar activities using the same variability index; and obtained a Gaussian distribution condition (equation 3) of about $70 \%$, and their results are well established.

For the seasonal pattern, we have made use of the mean monthly values and their standard deviation. In like manner, the annual average values and their corresponding standard deviation were used for the annual interpretation. The number of available values for the seasonal averaging during daytime and nighttime are 68-89 and 22-72, respectively. For the annual averaging, the numbers of available values are 272-341 and 68-334, respectively for the daytime and nighttime observations. The influence of spread-F on foF 2 values may be a reasonable factor for the availability of fewer data points during the nighttime.

\section{Results and discussions}

\subsection{Ionospheric foF2 observations}

Figure $1(\mathrm{a}-\mathrm{f})$ represents the average diurnal variation of the critical frequency (foF2) over Jicamarca for all seasons during low solar activity (LSA) years of 2010 and 2009 (figure 1a and b), moderate solar activity (MSA) years of 2004 and 2005 (figure 1c and d) and high solar activity (HSA) years of 2001 and 2002 (figures 1e and f). However, their average responses according to each solar activity period were reflected in figure $2(\mathrm{a}-\mathrm{c})$. We have shown in figure 1 the seasonal response of foF2 for each year, but we will analyse the response using figure 2; as it reflects the average foF2 response of each of the similar solar epoch duo years. From figure 2 in general, foF 2 increases from sunrise around 0500 LT and reaches its first peak (pre-noon peak) before 1200 LT around 0800-0900 LT for all seasons. The least foF2 magnitude was observed in winter around this period during the three solar epochs. Thereafter, there is a general daytime reduction in foF 2, reaching a minimum between 1030 and 1200 LT. The highest reduction was yet again in winter, while the least was during the equinox and followed by summer. Observations have shown that foF 2 increases after sunrise; the increase being more prominent at lower latitude. Maximum is reached in the early afternoon and there is a rapid decrease shortly after sunset. Around local noon, the F2 ionosphere had reached a dynamic stability with respect to losses by recombination, and production by solar radiation.

A second peak (the post-noon peak) was between 1500 and 1700 LT. This condition of the appearance 

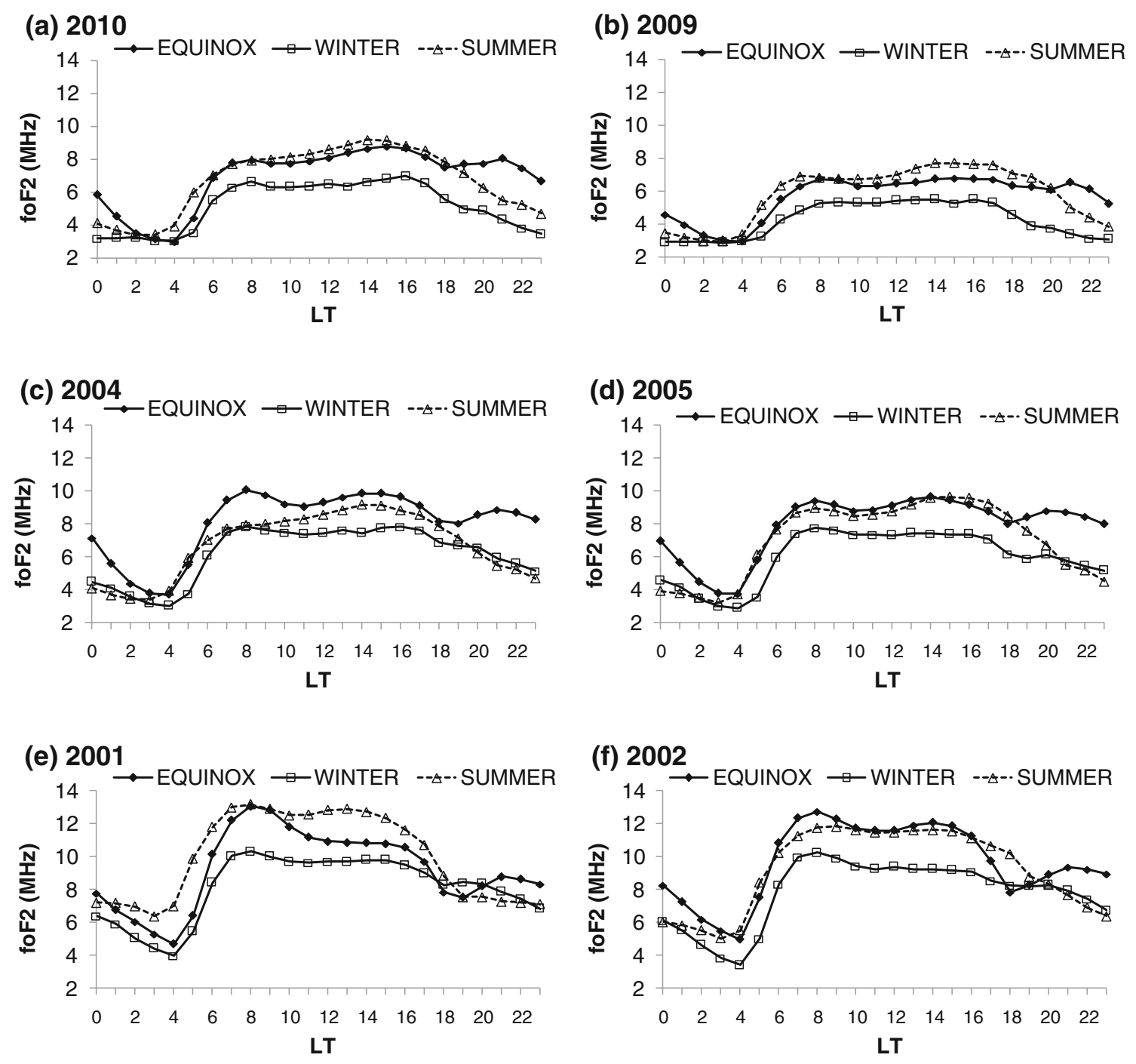

Figure 1. Diurnal variation of the critical frequency over Jicamarca for all seasons during years of low solar activity (a) 2010, (b) 2009, moderate solar activity, (c) 2004, (d) 2005 and high solar activity, (e) 2001 and (f) 2002.

of peak foF2 is highest during the summer for both LSA and HSA solar epochs, and equinox for the MSA period. During the entire solar epochs, the magnitude of the post-noon peak was least during the winter season. Concerning the nighttime variation of foF2 (1800-0600 LT), a general sharp drop is noticeable immediately after sunset. This sharp drop was around 1700 LT. This decay is continuous during the entire season until around $0400 \mathrm{LT}$, at which time a pre-sunrise minimum occurs. For this nighttime event, the critical frequency is lowest in winter and highest during the equinoctial months. (e.g., Liu et al. 2012). Both the observed pre-noon and afternoon foF2 peaks in the F2-layer and the variability, is due to variations of vertical $\mathrm{E} \times \mathrm{B}$ plasma drifts (e.g., Fejer et al. 1995; Fejer 1997; Adebesin et al. 2013a).

For the LSA period (figures $2 \mathrm{a}, 1 \mathrm{a}$ and $1 \mathrm{~b}$ ), the post-noon peak is a bit greater than the pre-noon peak. This observation is in total agreement with the results obtained for Ouagadougou $\left(12.4^{\circ} \mathrm{N}\right.$, $1.5^{\circ} \mathrm{E}$; dip $5.9^{\circ}$ ) by Radicella and Adeniyi (1999) during a low solar activity period. It is worth noting that during the MSA period (figures $2 \mathrm{~b}, 1 \mathrm{c}$ and $1 \mathrm{~d}$ ), the post-noon peak is almost equal in magnitude to the pre-noon peak for all seasons, except during summer, wherein the peaks are a bit different in magnitude. For the HSA period (figures 2c, $1 \mathrm{e}$ and $1 \mathrm{f}$ ), the post-noon peak is evidently lesser in magnitude than the pre-noon peak for all seasons. These observations are further interpreted on an annual basis using figure 3 . The figure depicts the diurnal variation of the critical frequency derived from the annual average values over all seasons for the different solar epochs. The LSA period recorded an average magnitude of $6.8 \mathrm{MHz}$ for the pre-noon peak, which is lesser than its post-noon peak value of $7.7 \mathrm{MHz}$. For the MSA years, both the pre-noon and the post-noon peaks recorded an approximate average value of $8.7 \mathrm{MHz}$. On the 
(a) LSA YEARS (2009 AND 2010) AVERAGE

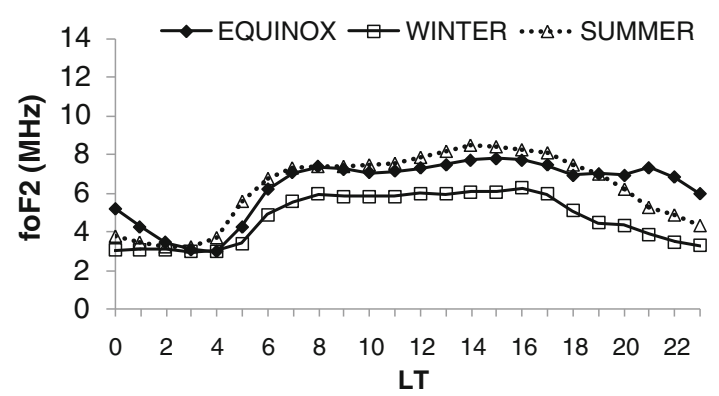

(b) MSA YEARS (2004 AND 2005) AVERAGE

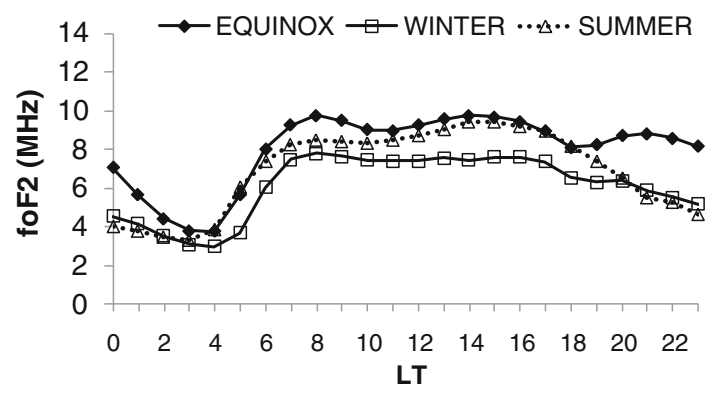

(c) HSA YEARS (2001 AND 2002) AVERAGE

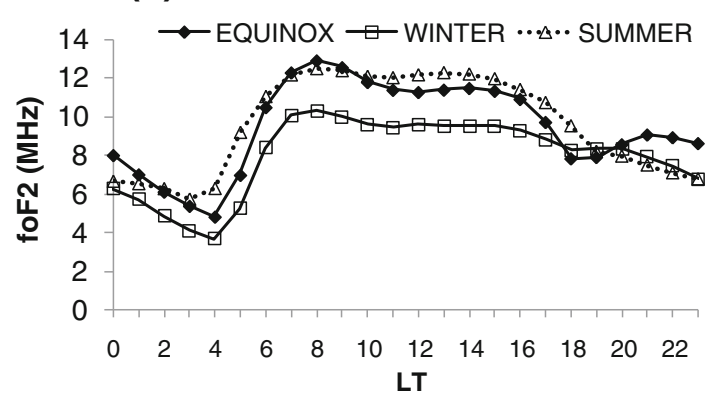

Figure 2. Diurnal response of the critical frequency over Jicamarca for all seasons for the averaged periods of (a) low solar activity, (b) moderate solar activity and (c) high solar activity.

other hand, the HSA years recorded pre-noon average peak value of $11.9 \mathrm{MHz}$, which is higher than the post-noon peak $(10.9 \mathrm{MHz})$. On an average, the ionospheric foF2 pre-noon peak magnitude seems to increase as the solar activity increases. This is also true for the post-noon peak, but to a lesser degree (magnitude). While the pre-noon magnitude increases by a factor of $\approx 2.3$ as we move up from low to high solar activity, the post-noon magnitude increases progressively by a factor of $\approx 1.2$ along the same path. It can therefore be suggested that the ionospheric foF 2 pre-noon peak magnitude intensifies by a factor of 2 more than the post-noon peak as the solar activity increases.

\subsection{Variability in foF2 relative standard deviation $V_{R}$}

Illustrated in figure $4(\mathrm{a}-\mathrm{f})$ are the diurnal plots of foF2 relative standard deviation for the

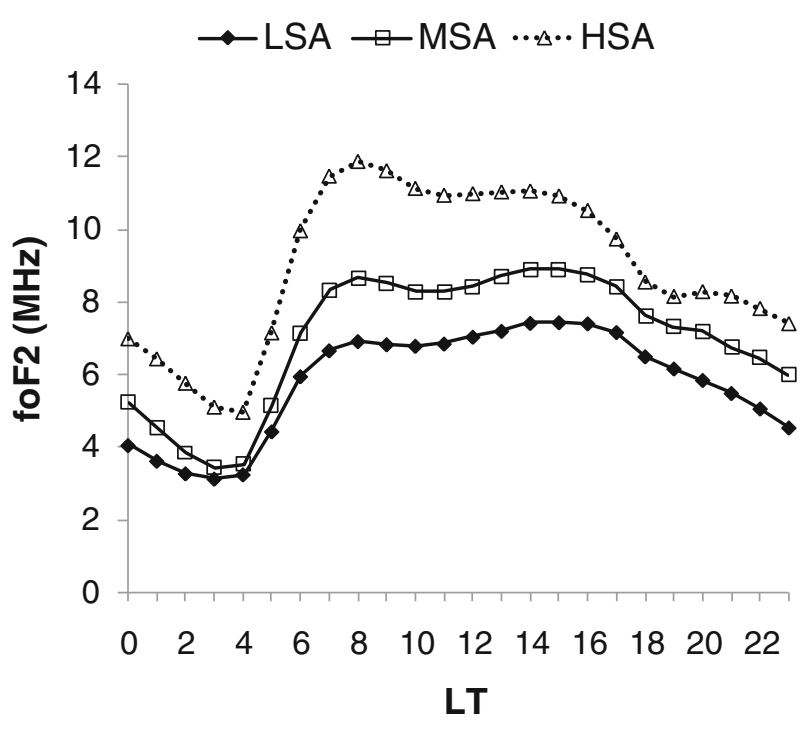

Figure 3. Diurnal variation of the critical frequency derived from annual average values over all seasons for the three solar epochs.

different solar epochs. Figure 4(a and b) is for the LSA period, figure $4(\mathrm{c}$ and $\mathrm{d})$ is for the MSA years, while the HSA period is represented by figure 4(e and $\mathrm{f})$. For a better and clearer comparison of the relative standard deviation during the entire solar epoch periods, we have averaged the results obtained from each of the two corresponding solar epoch years, and this is shown in figure $5(\mathrm{a}-\mathrm{c})$. For instance, figure $5(\mathrm{a})$ is the average result of figure $4(\mathrm{a}$ and $\mathrm{b})$. Each plot in figure 5 shows the variation of the variability index $V_{R}$ with local time (LT) for the entire three seasons. In general, similar trends were observed in the average diurnal variation of $V_{R}$ during the respective solar epochs. Variability is lowest during the day, ranging from $7-16 \%$ for the three solar epoch periods. $V_{R}$ thereafter increases during the night ranging from $20-26 \%, 14-26 \%$, and 10-20\%, respectively for the LSA, MSA, and HSA years. The highest magnitude was attained during sunrise (around $0400 \mathrm{LT}$ ) ranging from 21-27\%, $24-27 \%$, and $19-30 \%$, respectively for the LSA, MSA and HSA years. Note that two major peaks were evident from the entire plot: the pre-sunrise peak and the post-sunset peak. These peaks may not be unconnected with the sharp and abrupt density gradients, as indicated on the critical frequency plot in figure 1(a-f) between 1800 and 0400 LT which are caused by the onset and turnoff of solar ionization on the background electron density (Chou and Lee 2008), as well as the vertical plasma drift. However, the pre-sunrise peak seems to be higher than the post-sunset peak during the entire period of solar activities. The daytime and nighttime disparity according to Bilitza et al. (2004) is partly due to the lower mean value $(\mu)$ at night, 
(a) 2010

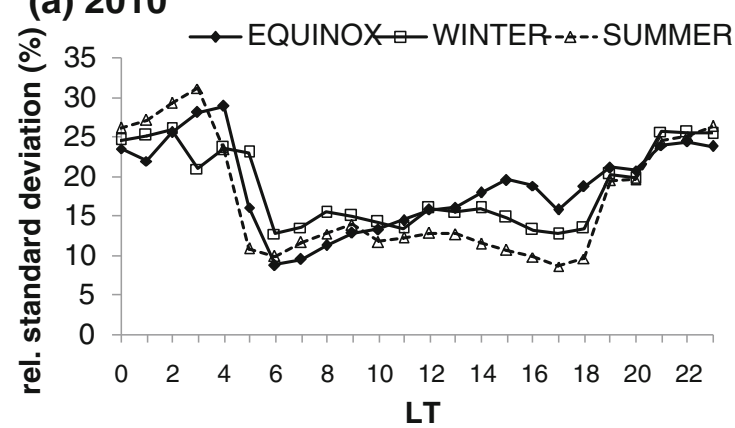

(c) 2004

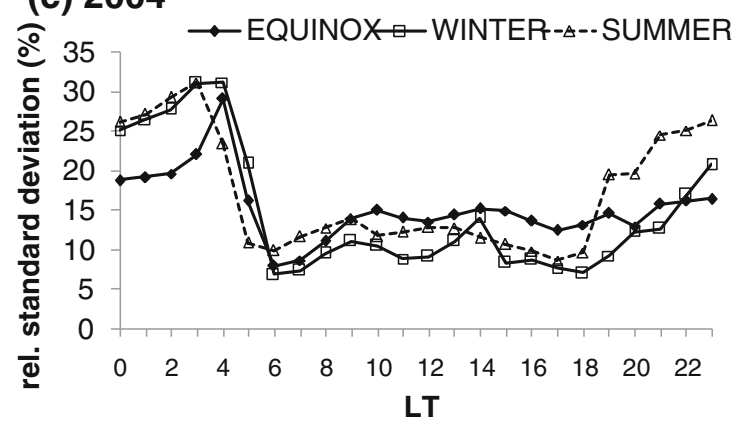

(e) 2001

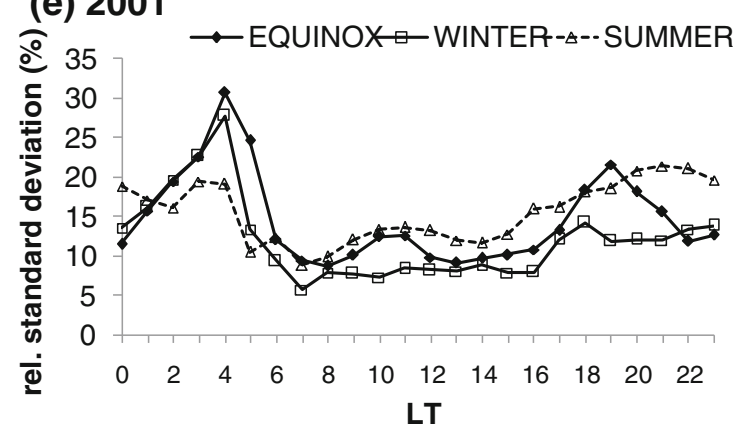

(b) 2009

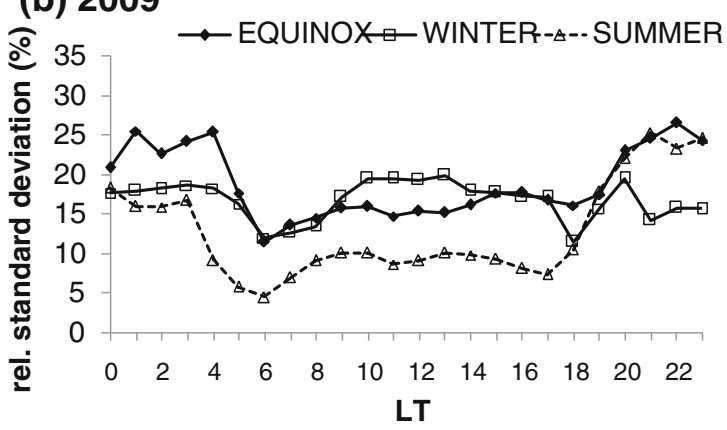

(d) 2005
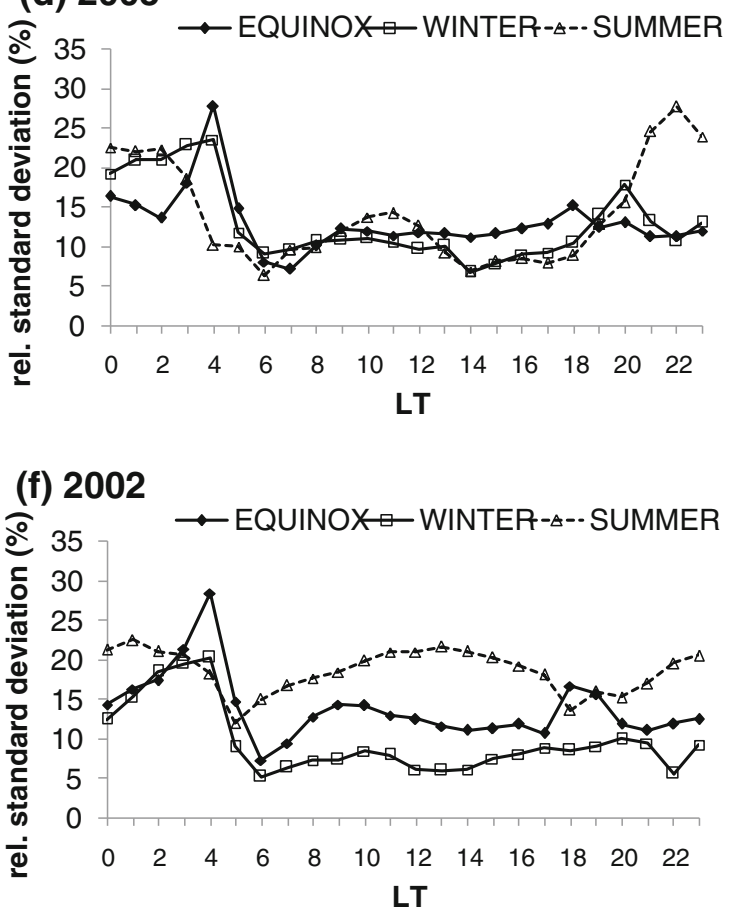

Figure 4. Diurnal plots of foF2 relative standard deviation $\left(V_{R}\right)$ over Jicamarca for all seasons during years of low solar activity (a) 2010, (b) 2009; moderate solar activity, (c) 2004, (d) 2005 and high solar activity, (e) 2001 and (f) 2002.

which for similar absolute variability results in a higher variability percentage during the night.

The highest pre-sunrise peak values were during the equinoctial months, while the lowest was in summer for the entire solar activity period. The pre-sunrise peak values in the variability coefficient $\left(V_{R}\right)$ during the equinox, winter and summer seasons range between $27-30 \%, 23-27 \%$ and $20-25 \%$, respectively. At local noon (1200 LT), $V_{R}$ ranges from $11-18 \%, 9-13 \%$ and $7-17 \%$ for the LSA, MSA and HSA years, respectively. The inference from the highest pre-sunrise foF 2 relative standard deviation variability during the equinoctial months suggests that there may be some other factors present during this season causing the variability, which may not necessarily be present during other seasons. This could be partly due to changes in tidal forcing, changes in the dynamic conditions at the base of the thermosphere, as well as the effects of planetary waves and irregular winds in the dynamo region; but more importantly caused by photochemistry (Ambili et al. 2012). Ambili et al. (2012) in a recent work had disclosed that the apparent surge (rise and fall motion) of the equatorial F-region peak at sunrise is produced majorly by photochemistry as against the general believed dynamics. They investigated the behaviour of the early morning ionosphere using a digisonde located at Trivandrum in India. They observed that as the peak rate of photo-ionization moves down in altitude and increases in magnitude, the newly formed charged particles (plasma) follow a comparable pattern. Subsequently, a jump, which was followed by a quick downward motion of the increasingly strong F-region peak altitude, was observed as the density becomes large enough to be detected by the digisonde. They concluded that the rationale behind the downward motion of the $\mathrm{F}$ peak 

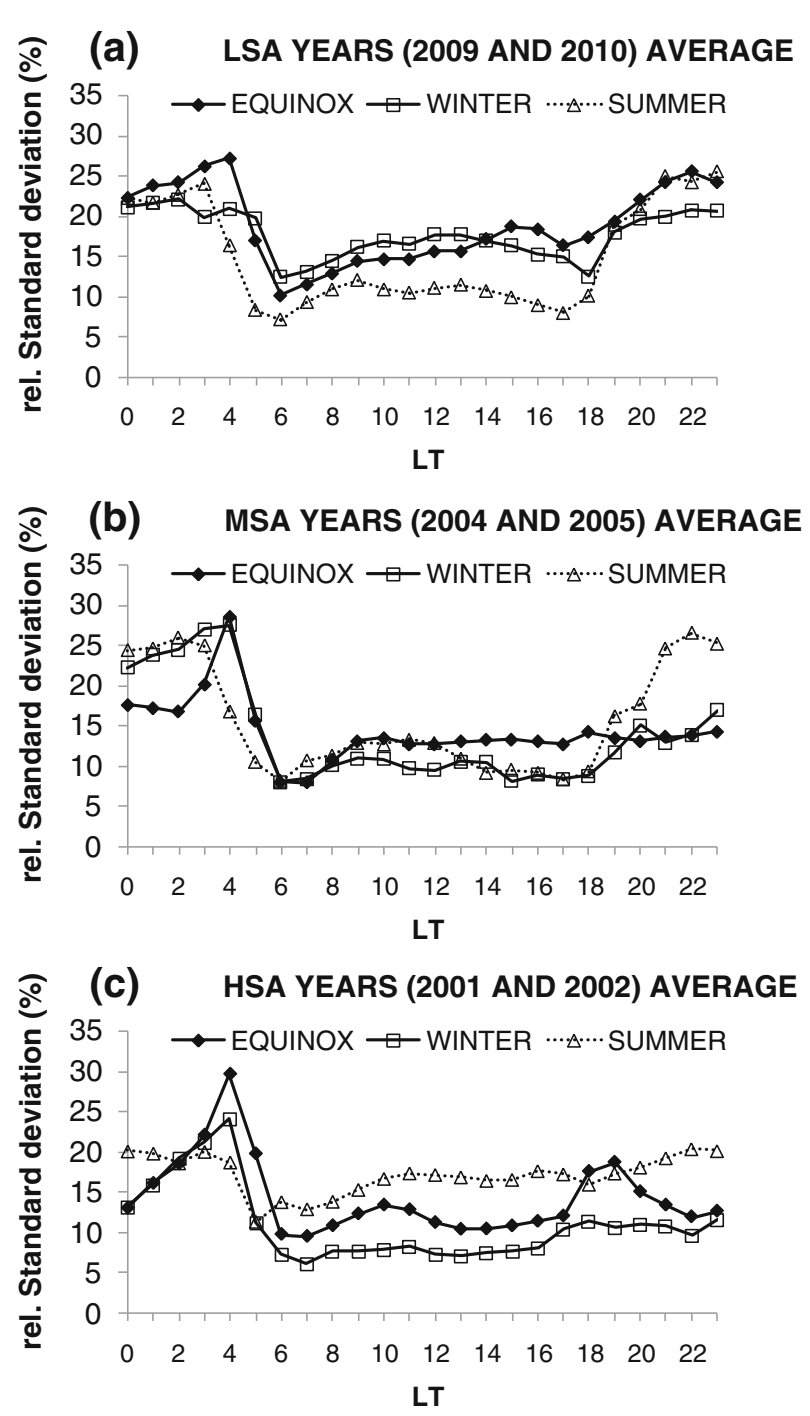

Figure 5. Diurnal response of foF2 relative standard deviation $\left(V_{R}\right)$ over Jicamarca for all seasons for the averaged periods of (a) low solar activity, (b) moderate solar activity and (c) high solar activity.

ending around $250 \mathrm{~km}$ is chemistry and not the usual electrodynamics, though electrodynamics plays an indirect role in the detection of the sunrise effect by simultaneously lowering both the peak height and density during the night. Adebesin et al. (2008) had also suggested that there is considerable intra-hour variability of foF2 during ionospheric disturbances.

The daytime minimum variability of between 7 and $16 \%$ observed during all solar epochs is consistent with the result of Bilitza et al. (2004) who recorded a value range of $5-15 \%$ over two African equatorial stations of Ouagadougou and Korhogo (lat. $9.3^{\circ} \mathrm{N}$, long. $5.4^{\circ} \mathrm{W}$, dip $\left.0.67^{\circ} \mathrm{S}\right)$; as well as the results of Oladipo et al. (2008) who recorded $3-10 \%$ for the same daytime period while investigating another equatorial station in the African region, during low solar activity periods.

Figure 6 presents the hourly value plot of foF 2 variability index calculated annually for Jicamarca during the three solar periods. From the figure, we observe that the strongest variation with solar activity is during nighttime. We can recall from section 2 that data that are more precise yield a smaller relative standard deviation. This suggests that the changes observed in the critical frequency variation are better represented during the daytime than at nighttime. This is because at night, the ionospheric electron density is dependent on the recombination rate, which is influenced by the gas compositions (Chou and Lee 2008) and equatorial electric field (EEF). At the equator, EEF causes vertical $\mathrm{E} \times \mathrm{B}$ plasma drift enhancement to altitude above F2-peak (Forbes 1981). The EEF is caused by the tidal winds in the Eregion, which drive ionospheric currents to higher latitudes. This current in turn interacts with the Earth's magnetic field and results in a building of positive and negative changes at the dawn and dusk terminal, respectively.

It has also been suggested that gravity waves could be responsible for the nighttime ionospheric density gradient enhancement. Hence the reason for the observed higher variability in foF 2 at nighttime rather than during daytime. However, the variability increases clearly as the solar activity decreases. The peak foF2 variability ranges from $23-24 \%$ for LSA period, $19-24 \%$ for MSA years, and $15-24 \%$ for HSA period, all on annual basis. The inverse relationship of increasing $V_{R}$ to decreasing solar activity is not so apparent between the MSA and HSA periods during the

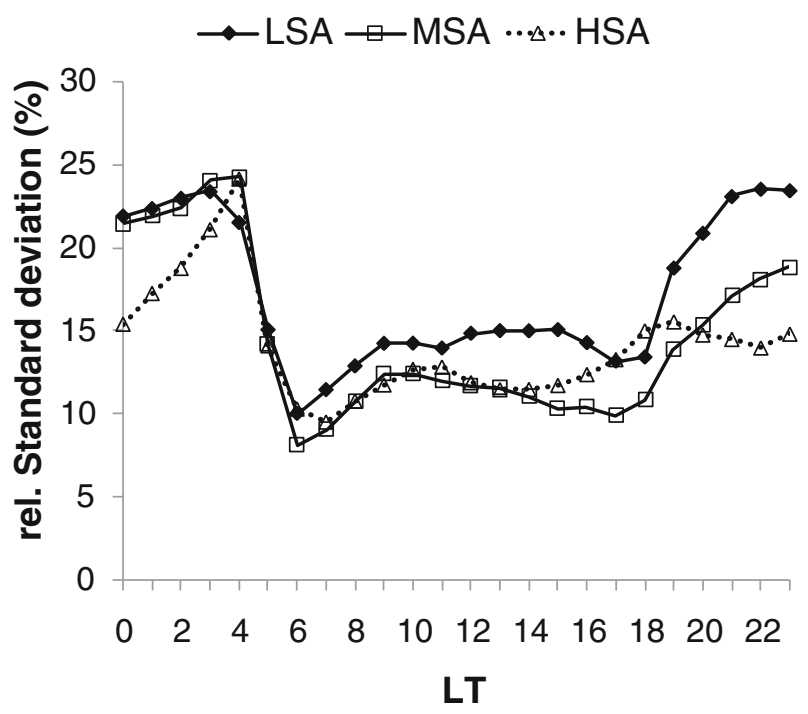

Figure 6. Diurnal variation of the foF 2 variability index $\left(V_{R}\right)$ derived from annual average values over all seasons for the three solar epochs. 
daytime. While almost equal variability magnitude was observed for MSA and HSA periods between 0600 and $1400 \mathrm{LT}$, the magnitude of the variability index during the MSA period is lower than that of the HSA years between 1700 and 2000 LT. However, the variability index is still maximum during the LSA period at daytime. This is because foF2 increases (see figure 3) with increasing solar activity, and consequently, the variability percentage increases.

Figure $7(\mathrm{a}-\mathrm{c})$ shows the respective regression plot between the critical frequency (foF2) and its corresponding relative standard deviation $\left(V_{R}\right)$ for the three solar epochs. The data-points are the mean hourly values for each of the months considered for respective years of each solar activity period. We observed correlation coefficient values of $0.71,0.52$, and 0.46 for the LSA, MSA, and HSA years, respectively. This also affirms that the variability of the critical frequency increases with reducing solar activity.

It is worth mentioning that the downward foF2 perturbation apart from the photochemistry effect, could have been due to increase (upward or eastward electric field increase) in vertical drifts. Ionospheric plasma is raised by this drift beginning from the F2 region, and then drifts along the magnetic field lines apart from the geomagnetic equator. Moreover, neutral composition changes observed at equatorial latitudes may not be sufficient to cause depletion in foF 2 variations, but an increase in atomic oxygen $[\mathrm{O}]$ may contribute to the enhancement in foF 2 variability when $\mathrm{E} \times \mathrm{B}$ drifts are small. $[\mathrm{O}]$ is predominantly the largest atomic gas present in the F2 region (table 2). It is important to emphasize that the increase of absolute atomic oxygen concentration provides a background foF 2 increase. On the other hand, a very strong downward drift (or westward electric field) may also result in downward foF2 variability effect when F2 layer is pushed down to lower heights where recombination is strong (Mikhailov and Leschinskaya 1991).

\subsection{Response of $h m F 2$ and effects of vertical plasma drifts}

The response of the F2-layer height of peak electron density $(\mathrm{hmF} 2)$ is illustrated in figure $8(\mathrm{a}-$ $\mathrm{f}$ ), which are the respective hmF2 observations for the low, moderate and high solar activity years, and span the entire equinox, winter and summer seasons. Figure $9(\mathrm{a}-\mathrm{c})$ highlights the average plots of the respective solar epoch periods. The observations for hmF2 (from figure 9) for the entire season and all solar epochs indicate a sharp and gradual rise within the duration of 0600-1400 LT for the LSA and MSA years, and within 0600-1600 LT for the HSA year. The variation range between respective seasons during the different solar epochs between 1600 and 2300 LT is much broader. The peak magnitude of $\mathrm{hmF} 2$ within this period ranges from 298-392 km for LSA years, 333-418 km for MSA years, and 416-526 km for HSA years. For all the daytime observations, the HSA period hmF2 height is raised higher than the MSA and LSA (a) LSA YEARS 2009 AND 2010

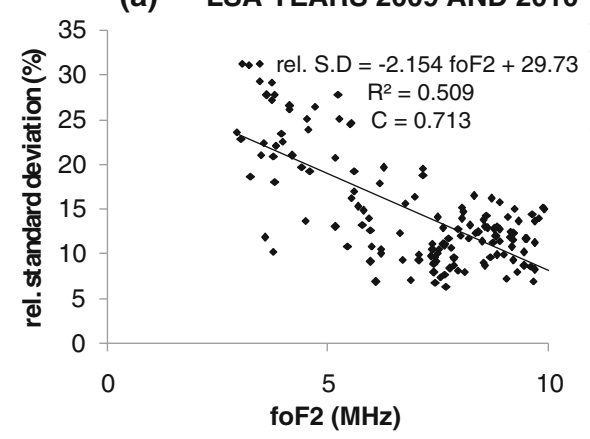

(b)

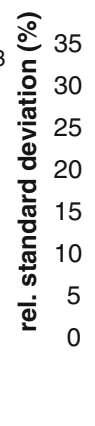

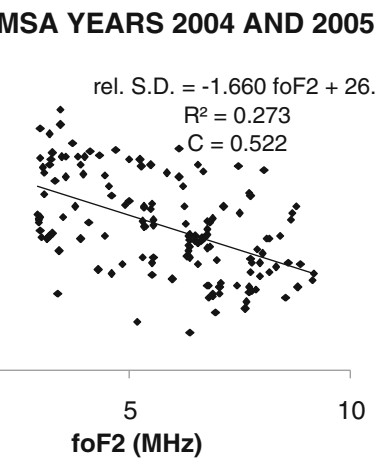

(c) HSA YEARS 2001 AND 2002

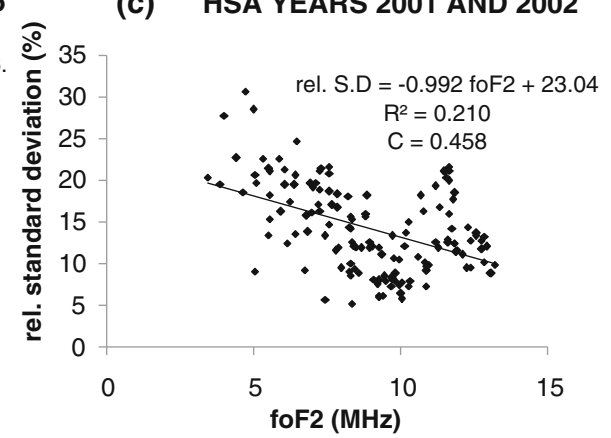

Figure 7. Regression plot of foF 2 and $V_{R}$ for the three solar epochs.

Table 2. Types of atoms/molecules and maximum number of electrons in each region (after Oyinloye 1988).

\begin{tabular}{lcl}
\hline Regions & Atom/molecule present & \multicolumn{1}{c}{ Maximum no. of electrons } \\
\hline $\mathrm{D}$ & $\mathrm{N}_{2}, \mathrm{O}_{2}$ & $10^{8}-10^{10}$ electron $/ \mathrm{m}^{3}$ (day) \\
$\mathrm{E}$ & $\mathrm{N}_{2}>\mathrm{O}_{2}>\mathrm{O}$ & $10^{11} \mathrm{e} / \mathrm{m}^{3}$ (day), $10^{9} \mathrm{e} / \mathrm{m}^{3}$ (night) \\
$\mathrm{F}_{1}$ & $\mathrm{~N}_{2}>\mathrm{O}>\mathrm{O}_{2}$ & $10^{12} \mathrm{e} / \mathrm{m}^{3}$ (day) \\
$\mathrm{F}_{2}$ & $\mathrm{O}>\mathrm{N}_{2}>\mathrm{O}_{2}$ & $10^{12} \mathrm{e} / \mathrm{m}^{3}$ (day), $5 \times 10^{10} \mathrm{e} / \mathrm{m}^{3}$ (night) \\
\hline
\end{tabular}



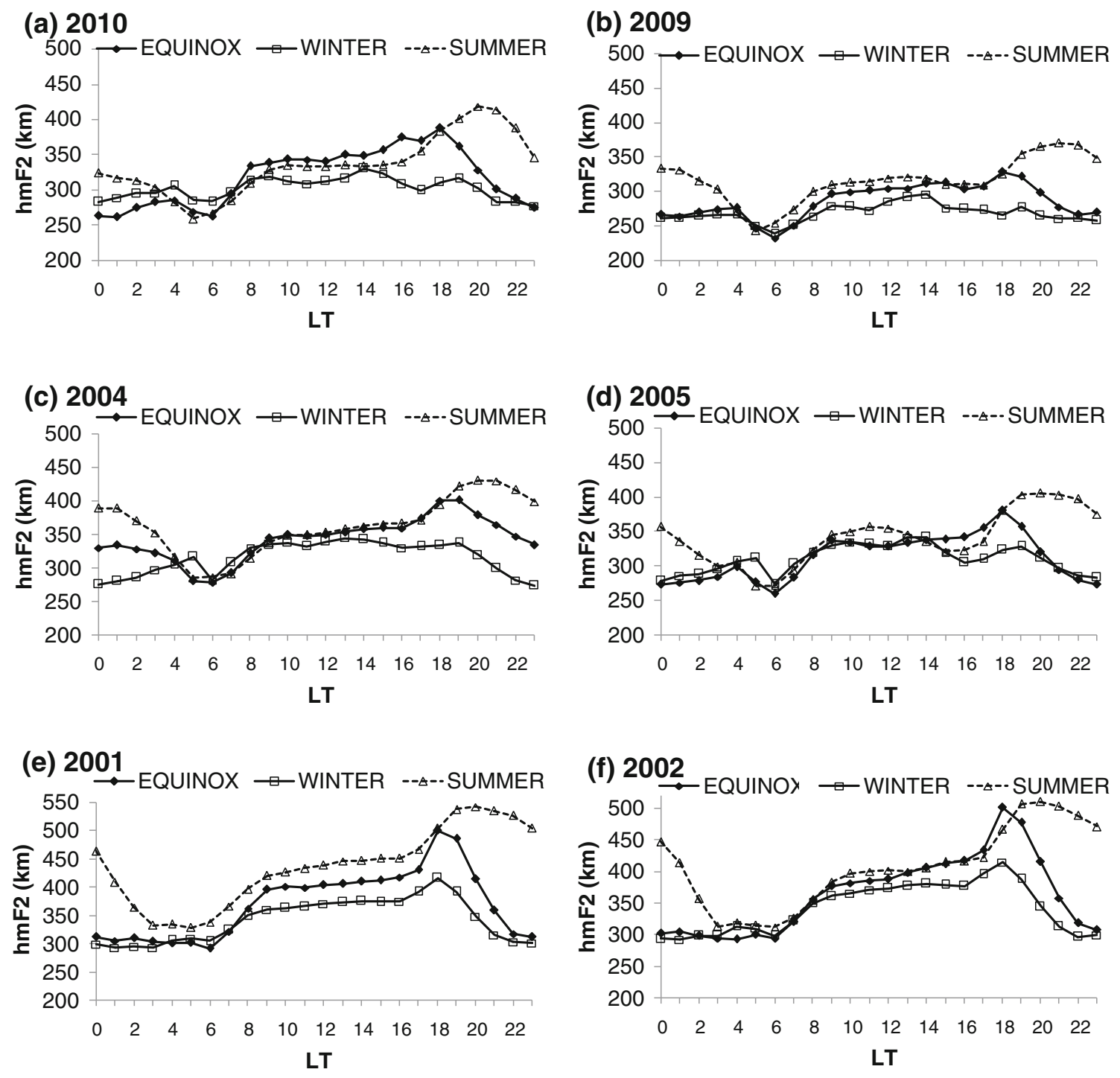

Figure 8. Diurnal plots of height of the peak electron density (hmF2) over Jicamarca for all seasons during years of low solar activity (a) 2010, (b) 2009; moderate solar activity, (c) 2004, (d) 2005 and high solar activity, (e) 2001 and (f) 2002.

years. For all the solar epochs, hmF2 was raised highest during the equinoctial months, while the lowest was recorded in winter.

The average annual hourly values of hmF2 over Jicamarca during the solar epochs are presented in figure 10. The figure revealed that the average prenoon peaks for the LSA, MSA, and HSA periods, which are apparently not so distinct, are respectively 388,342 and $313 \mathrm{~km}$. Their peak occurrence times are around 1000 LT. Moreover, the second peak (post-noon peak) had respective peak values of 467, 375 and $339 \mathrm{~km}$ in similar order, occurring around $1800 \mathrm{LT}$. The inference we can draw from this statement is that the ionospheric F2-layer height is raised with increasing solar activity. The lifting of the F2-layer after local sunset is a result of (i) recombination of molecular ions in the lower Fregion, and (ii) the electrodynamical lifting of the F-region.
According to Adebesin et al. (2013a, c), variation in the F2 region is not as simple as that of the lower region. The influence of space weather on the distribution of ionization driven by $\mathrm{E} \times \mathrm{B}$ force may be responsible for the complex nature of the variation in the F2 heights. Hanson and Moffett (1966) were the first to demonstrate the contribution of $\mathrm{E} \times \mathrm{B}$ drift in controlling the plasma density at the dip-equator and in the anomaly region. They obtained solutions of the continuity equation for the electrons in the $\mathrm{F} 2$ region of the ionosphere using the physical processes of photoionization, recombination, diffusion, neutral winds, and electromagnetic drift, and concluded that upward plasma drift of about $10 \mathrm{~m} / \mathrm{s}$ at the equator is very likely the cause of the Appleton anomaly. Fejer and Scherliess (1997) had also observed the alteration of the morphology of the $\mathrm{F} 2$ region by the $\mathrm{E} \times \mathrm{B}$ drifts, the thermospheric neutral winds 

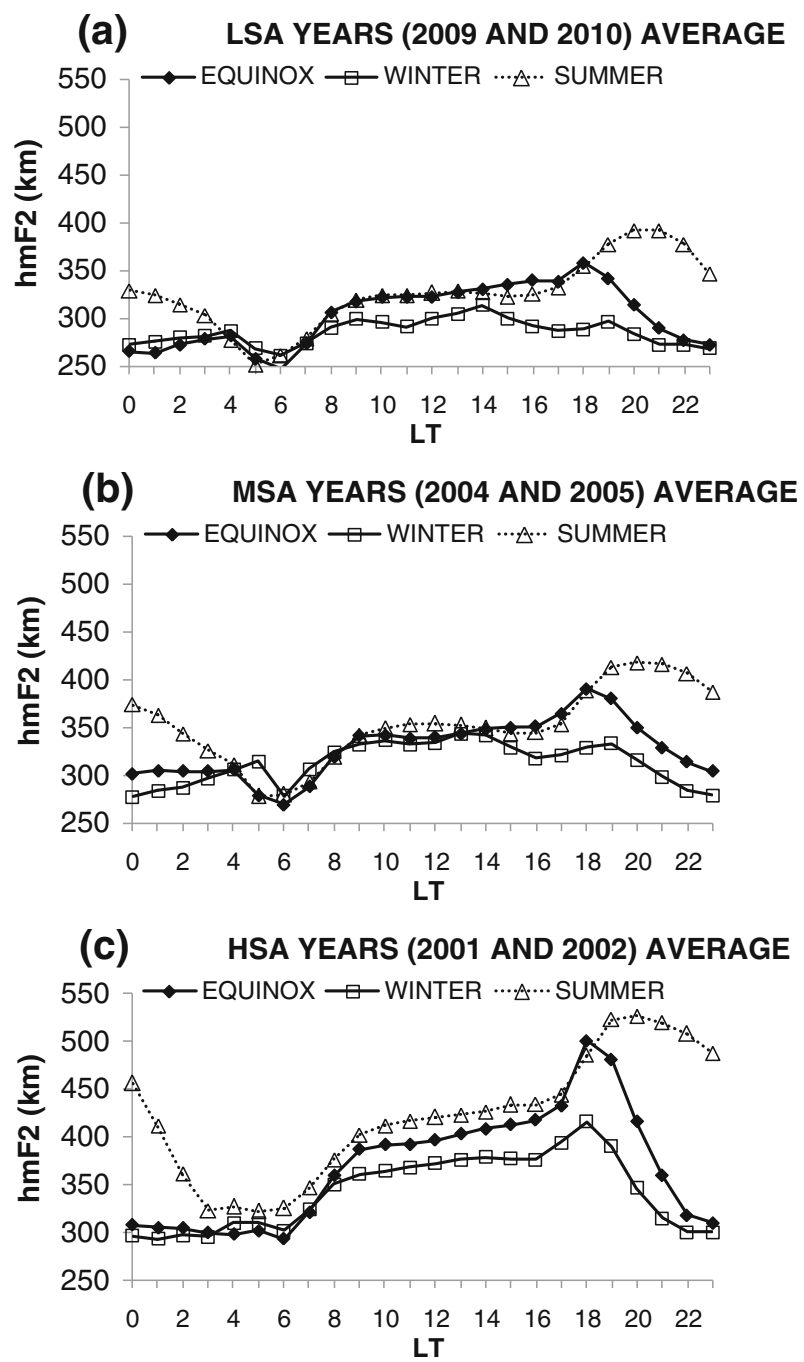

Figure 9. Diurnal response of hmF2 over Jicamarca for all seasons for the averaged periods of (a) low solar activity, (b) moderate solar activity and (c) high solar activity.

latitudinal variation, the development of the Appleton anomaly, and the low-latitude protonospheric ion composition. Consequently, several other works (e.g., Radicella and Adeniyi 1999; Scherliess and Fejer 1999; Anderson et al. 2002; Dabas et al. 2003; Obrou et al. 2003; Woodman et al. 2006; Uemoto et al. 2010; Adebesin et al. 2013a, b) had shown relationships between the vertical $\mathrm{E} \times \mathrm{B}$ drifts and the electron density (NmF2), foF2 and hmF2; while their significant variation with local time, season, solar cycle, and geomagnetic longitude are well documented.

According to Oladipo et al. (2008 and the reference therein), in the equatorial region, the $\mathrm{E} \times \mathrm{B}$ field contributes to the vertical drift of ionization around the equator resulting in the depletion of ionization during the daytime. Hence, such kinds of vertical plasma motions are primarily accountable for the deviations in the F2 layer parameters in the

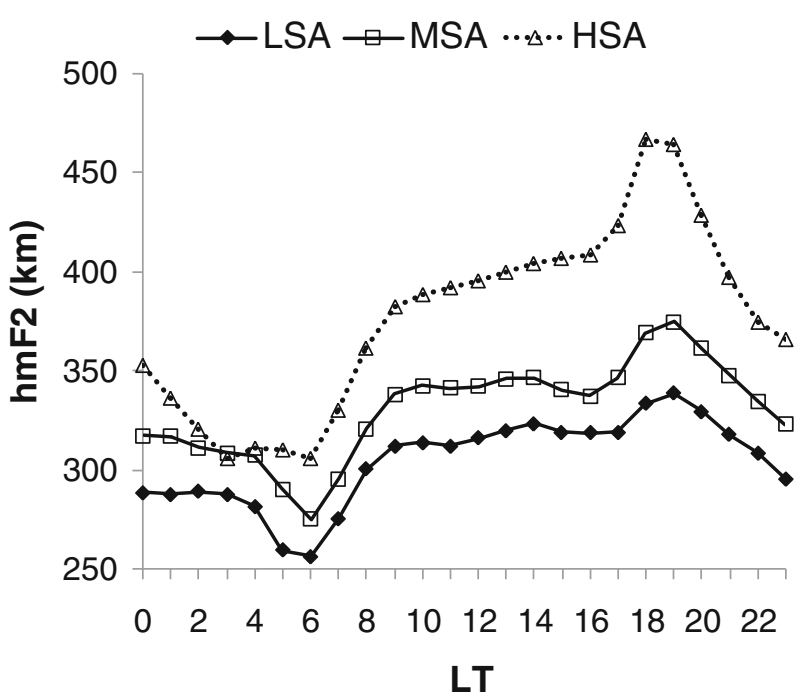

Figure 10. Diurnal variation of hmF2 derived from annual average values over all seasons for the three solar epochs.

equatorial ionosphere. Rajaram and Rastogi (1977) as well as Radicella and Adeniyi (1999) had studied the equatorial ionospheric electron density below the F2 peak. Their results showed that the effect of $\mathrm{E} \times \mathrm{B}$ drift on the equatorial ionosphere commences from an altitude of about $200 \mathrm{~km}$ upwards, which may explain the distinct variability observed in this study.

From the results of Adebesin et al. (2013a, b) at evening time, the F2 region vertical plasma drifts and the corresponding electric fields are characterized by a sharp enhancement after sunset, usually referred to as the pre-reversal enhancement (PRE). The PRE is believed to be generated by the combined $\mathrm{F} 2$ region dynamo action driven by the eastward thermospheric wind close to dusk as well as the action of the E-region conductivity changes near the sunset terminator at conjugate magnetic latitudes (Risbeth 1971). According to Abdu et al. (1993), the PRE displays significant variability, which predominantly depends on contributions from E-region dynamo, variations in F-region wind, equatorial electrojet strength (EEJ) and changes in the ratio of $\mathrm{E} / \mathrm{F}$ region conductivity. Recently, Sumod et al. (2012 and the references therein) and Adebesin et al. (2013b) have shown that lower atmospheric forcing (tides and waves) can also make substantial changes to the PRE. Therefore, a good understanding of the PRE and the pre-sunrise plasma drift would provide a clearer insight into the ionospheric variability of foF2. It is well established that vertical drifts during the daytime are upward, peaking around 1000 LT. This would make electrons to go up and away from the equator causing the maximum daytime electron depletion and hence foF 2 depletion around local noon (figure $2 \mathrm{a}-\mathrm{c}$ ) since both $\mathrm{NmF} 2$ and foF2 
are directly related by the formula foF $2(\mathrm{MHz})=$ $9.0 \times[\mathrm{NmF} 2]^{1 / 2} \mathrm{~m}^{-3}$. The sudden faster electron drift away from the equator in rising plasma drift may not be unconnected with the sharp drop in foF2 immediately after sunset.

\subsection{Comparison between observed foF2 and IRI-2012 model}

According to Adebesin et al. (2013c and the references therein), the International Reference Ionosphere (IRI) Task Force Report suggested that the study of the electron density variability, and hence, the critical frequency can be achieved in two ways. These are (a) by investigating the variability at each height or (b) by relying on the peak parameters (hmF2, foF2) among other profiles. The latter approach is best suited for studying the variability of the peak parameters. In bid of these, we intend to compare our observed foF2 with the IRI-2012 model in this section, and to also validate the accuracy of the observed data used. The two model options (URSI and CCIR) were used for the comparison. Similar comparisons were reported in the work of Alagbe (2012), Olawepo and Adeniyi (2012) and Adebesin et al. (2013c) using the IRI-2007 model. The IRI model was provided by the United States National Oceanic and Atmospheric Administration (NOAA) and is available on the website http://omniweb.gsfc.nasa.gov/ vitmo/iri_vitmo.html. Here, we compare our foF2 observed data with the corresponding IRI-2012 model. Because of space consideration, we have selected only one year each from each solar activity period to make the comparison. These are 2010, 2004, and 2001 for the low, moderate and high solar activity periods, respectively.

Figures $11(\mathrm{a}-\mathrm{c}), 12(\mathrm{a}-\mathrm{c})$ and $13(\mathrm{a}-\mathrm{c})$, respectively depict the comparison plots between the observed (Jicamarca) response and the IRI-2012 model for the LSA (2010), MSA (2004) and HSA (2001) periods for the entire three seasons. The vertical bar on each of the observed plots in all the figures indicates the respective standard deviation about the mean for each of the seasons. For the LSA year in figure 11, the observed response at Jicamarca revealed a better fit with both IRI options during the equinoctial months (figure 11a) than during the other two seasons. For this low solar activity event, the observed data was a bit underestimated by both options at daytime between 0400 and $0800 \mathrm{LT}$, balances within the time range of 0800-1600 LT, and was overestimated within 17002300 LT for the entire three seasons. However, most of this overestimation/underestimation by the IRI model had been made up for, by the standard deviation in the observed data, suggesting little or
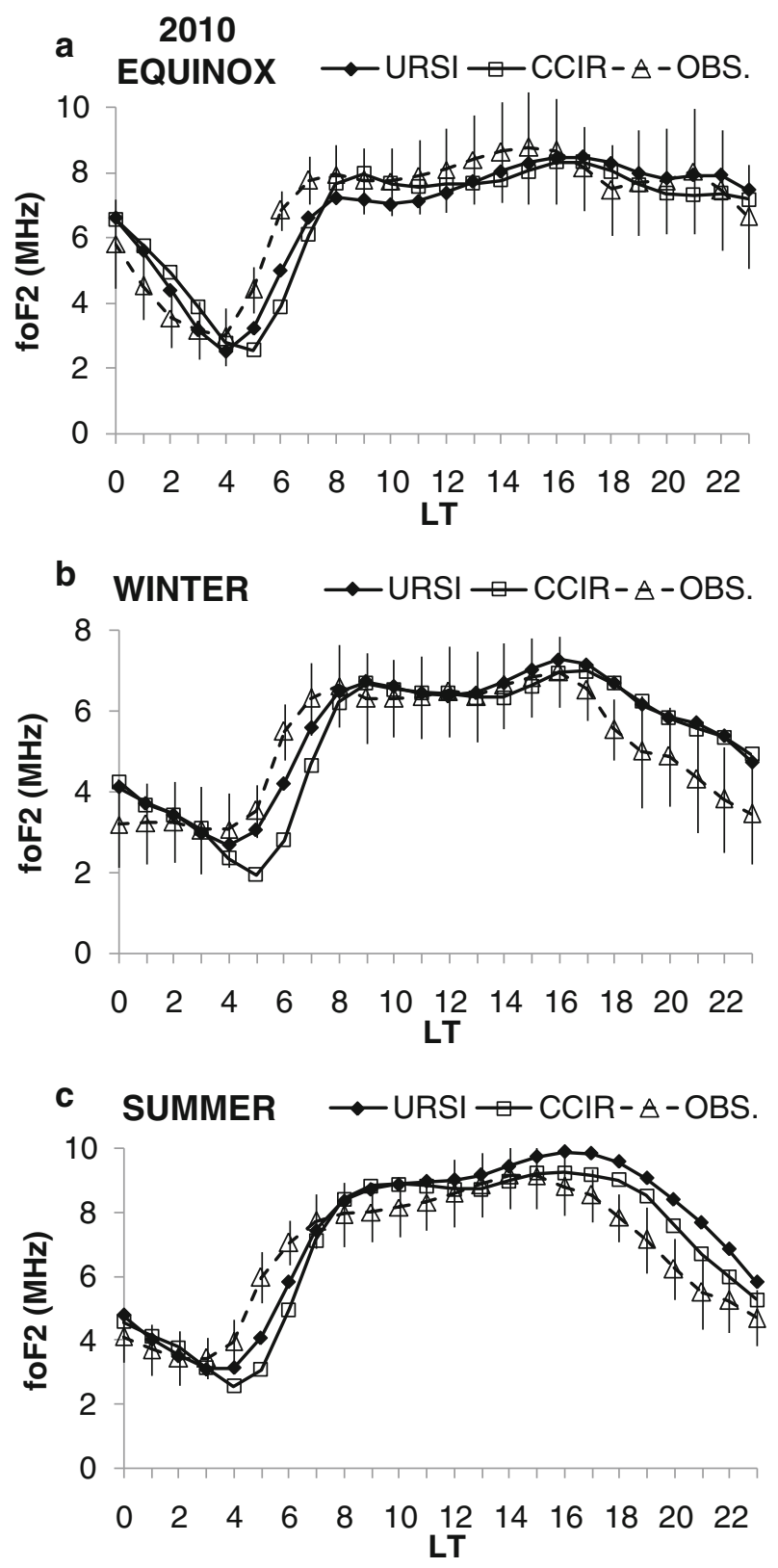

Figure 11. Comparison plot between observed foF2 and IRI2012 model (CCIR and URSI options) for the low solar activity year 2010 at Jicamarca during (a) equinox, (b) winter and (c) summer seasons.

no significant difference. This is because most of this standard deviation falls within the range of the model. Hence, we can qualitatively report that the observed data over Jicamarca is well represented by the model. This is not surprising, as the model is based on results majorly from Jicamarca measurements (both ground-based and space-borne). For this LSA event, the URSI option performed better during the day, while the CCIR performed better at night. Figure $12(\mathrm{a}-\mathrm{c})$ representing the MSA year 2004 revealed a slight underestimation of the observed plot for all seasons between 0400 and 0900 LT. There is however, a better fit between the 

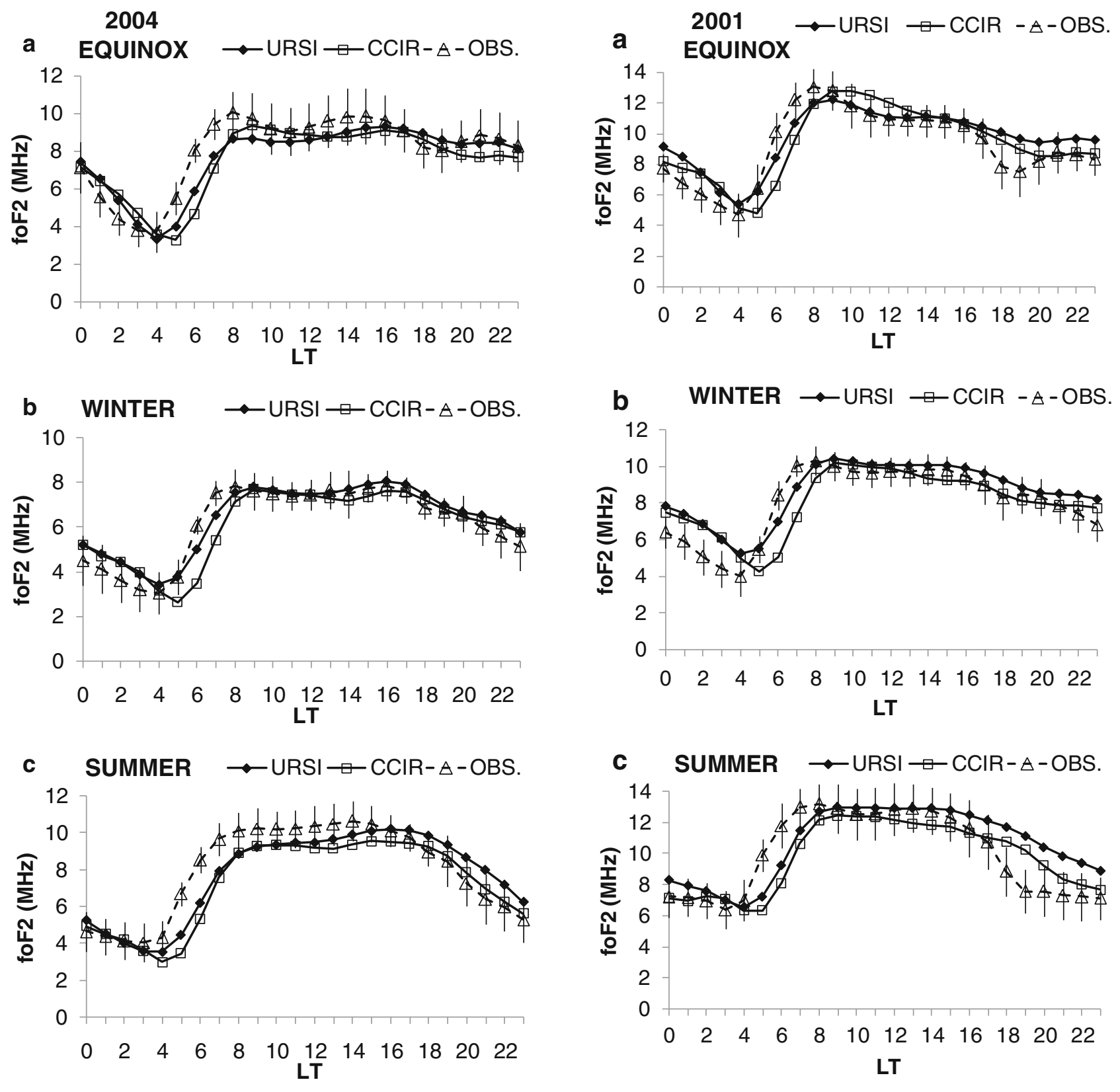

Figure 12. Same as in figure 11, but for moderate solar activity year 2004 .

Figure 13. Same as in figure 11, but for high solar activity year 2001.

observed and the modelled options for the remaining period for the entire season especially during the night. The URSI option here again performed better between 0400 and $1000 \mathrm{LT}$, and the fit was almost equal for the remaining part of the hours. The HSA year in figure $13(\mathrm{a}-\mathrm{c})$ revealed similar patterns as in figure 12. Based on these observations, we can deduce that the Jicamarca equatorial station is better represented on the IRI model, irrespective of the solar activity period. This is consistent with the result obtained by Adebesin et al. (2013c) when comparing the result over Jicamarca with the IRI-2007 model during storm-time

geomagnetic activity event of 9 March 2012. In general, the URSI option was observed to align better with the observed than the CCIR option, especially during daytime. This suggests an improvement in the URSI option of the IRI-2012 model over the IRI-2007 model. This is because Adebesin et al. (2013c) had reported a better fit for the CCIR option than the URSI option of the IRI-2007 model, even during the daytime period at Jicamarca. Olawepo and Adeniyi (2012) too had earlier observed a better fit of the observed data with the CCIR option of IRI-2007 during the daytime than the URSI option during an investigation of 
the peak electron density $(\mathrm{NmF} 2)$ response to the 14-16 December, 2006 geomagnetic storm.

\section{Summary and conclusion}

We have investigated both the diurnal, seasonal, and annual foF2 variability and the response of the F2-layer over a South America sector equatorial station during different solar activity periods. We employed the relative standard deviation for our analysis. The F2-layer critical frequency pre-noon peak magnitude increases with increasing solar activity. This is also true for the post-noon peak, but to a lesser degree - the pre-noon peak magnitude intensifies by a factor of 2 more than the post-noon peak, as the solar activity increases.

Variability coefficient $\left(V_{R}\right)$ is lowest during the day ranging from $7-16 \%$ for the three solar epoch periods. $V_{R}$ thereafter increases during the night ranging from $20-26 \%, 14-26 \%$, and $10-20 \%$, respectively for the LSA, MSA, and HSA years. The highest magnitude was attained during sunrise (around $0400 \mathrm{LT}$ ) ranging from $21-27 \%, 24-$ $27 \%$, and $19-30 \%$, respectively for the LSA, MSA and HSA years. Two major peaks observed were the pre-sunrise peak and the post-sunset peak. These were attributed to the sharp density gradients caused by the onset and turnoff of solar ionization on the background electron density; as the lifetime of a free electron is of the order of hours Hines et al. (1965), hence, the ionization equilibrium can be strongly affected by the movements of electrons that result from electromagnetic forces, temperature changes and diffusion. $V_{R}$ pre-sunrise peak is higher than the post-sunset peak during the entire solar activity. The variability increases as the solar activity decreases. Annually, $V_{R}$ peaks range within $23-24 \%, 19-24 \%$, and $15-24 \%$ for the LSA, MSA, and HSA periods, respectively. The inverse relationship of increasing $V_{R}$ to decreasing solar activity is also continual during the daytime but with smaller absolute change.

The highest pre-sunrise peak values were during the equinoctial months, while the lowest was in summer for all the solar activity periods. The pre-sunrise peak values in the variability coefficient $\left(V_{R}\right)$ during the equinox, winter and summer seasons range within $27-30 \%, 23-27 \%$ and $20-25 \%$, respectively. At local noon, $V_{R}$ ranges from 11$18 \%, 9-13 \%$ and $7-17 \%$ for the LSA, MSA and HSA years, respectively.

The ionospheric F2-layer height is raised to higher levels with increasing solar activity. The peak hmF2 magnitude ranges within 298-392 km for LSA years, 333-418 km for MSA years, and 416-526 km for HSA years. The relevance of $\mathrm{E} \times \mathrm{B}$ drift is briefly mentioned in understanding more of the ionospheric variability of foF 2 . This, we intend to undertake in our future work. The foF 2 results revealed that Jicamarca is well represented on the IRI-2012 model, though with an improvement on the URSI option especially during the daytime. This may not be unconnected with the fact that majority of the equatorial ISR measurements have been collected at Jicamarca, so that much of our understanding of the equatorial ionosphere is based on Jicamarca ISR observations, which is in the American sector where the geomagnetic equator dips, yielding fairly large excursions between the geomagnetic and geodetic equator. Some past results were also validated.

\section{Acknowledgements}

The authors acknowledge United States National Oceanic and Atmospheric Administration (NOAA) for providing the foF2 data from the IRI-2012 website at http://omniweb.gsfc.nasa.gov/vitmo/iri_ vitmo.html, as well as the Space Physics Interactive Data Resource (SPIDR) centre website (http:// spidr.ngdc.noaa.gov) for the observational foF2 and hmF2 data used. One of the authors (B O Adebesin) is grateful to the Editor and the two reviewers for the wonderful job they have done on the original draft of the paper. Their constructive comments and suggestions have led to reprocessing many of our important plots and reanalyzing them, especially the inclusion of more than oneyear data in identifying different solar epochs and in the importance of using the relative standard deviation as our variability index. The solar flux at $10.7 \mathrm{~cm}\left(\mathrm{~F}_{10.7}\right)$ for characterizing solar activity is obtained from the NSSDC's OMNI database website (http://nssdc.gsfc.nasa.gov/omniweb).

\section{References}

Abdu M A, Fejer B G, Batista I S, Sobral J H A and Szuszczewicz E P 1993 Equatorial ionosphere sunset electrodynamics in the American sector from SUNDIAL December 1988 campaign results; Geomagn. Aeron. 33(1) $13-19$.

Adebesin B O, Adeniyi J O, Adimula I A and Reinisch B W 2013a Equatorial vertical plasma drift velocities and electron densities inferred from ground-based ionosonde measurements during low solar activity; J. Atmos. Sol. Terr. Phys. 97 58-64, doi: 10.1016/j.jastp.2013.02.010.

Adebesin B O, Adeniyi J O, Adimula I A, Reinisch B W and Yumoto K 2013b F2 layer characteristics and electrojet strength over an Equatorial station; Adv. Space Res. 52(5) 791-800, doi: 10.1016/j.asr2013.05.025.

Adebesin B O, Ikubanni S O, Adebiyi J S and Joshua B W 2013c Multi-station observation of ionospheric magnetic disturbance of March 9, 2012 and comparison with IRI model; Adv. Space Res. 52(4) 604-613, doi: $10.1016 /$ j.asr2013.05.002. 
Adebesin B O 2012 foF2 variations during geomagnetic disturbances at the rise of solar cycle 23; Indian J. Radio Space Phys. 41(3) 323-331.

Adebesin B O, Bakare N O and David T W 2008 Variability in the F1 and F2 region electron density during a geomagnetic activity at mid-latitude; J. Environ. Ext. 7 $48-55$.

Adeniyi J O, Oladipo O A and Radicella S M 2007 Variability of foF 2 for an equatorial station and comparison with the foF2 maps in IRI model; J. Atmos. Sol. Terr. Phys. $69721-733$.

Alagbe G A 2012 Geomagnetic storm effects on F2 layer peak electron density and other profile parameters at high solar activity at an equatorial station; J. Phys. Sci. Innovation 4 5-12, ISSN 2277-0119.

Akala A O, Somoye E O, Adeloy A B and Rabiu A B 2011 Ionospheric foF 2 variability at equatorial and low latitudes during high, moderate and low solar activity; Indian J. Radio Space Phys. 40 124-129.

Ambili K M, St-Maurice J-P and Choudhary R K 2012 On the sunrise oscillation of the $\mathrm{F}$ region in the equatorial ionosphere; Geophys. Res. Lett. 39 L16102, doi: 10.1029/2012GL052876.

Anderson D, Anghel A, Chau J, Yumoto K, Bhattacharyya A and Alex S 2006 Daytime, low latitude, vertical $\mathrm{E} \times \mathrm{B}$ drift velocities, inferred from ground-based magnetometer observations in the Peruvian, Philippine and Indian longitude sectors under quiet and disturbed conditions; ILWS WORKSHOP, GOA, February 19-24, 2006, pp. 1-6.

Anderson D N, Anghel A, Yumoto K, Ishitsuka Yumoto $\mathrm{K}$ and Kudeki E 2002 Estimating daytime, vertical $\mathrm{E} \times \mathrm{B}$ drift velocities in the equatorial f-region using ground-based magnetometer observations; GRL 29 12, doi: 10.1029/2001GL014562.

Atac A, Ozguc A and Pektas R 2009 The variability of foF2 in different phases of solar cycle 23; J. Atmos. Sol. Terr. Phys. 71 583-588.

Batista I S and Abdu M A 2004 Ionospheric variability at Brazillian low and equatorial latitudes: Comparison between observations and IRI model; Adv. Space Res. 34 1894-1900.

Bilitza D, Obrou O K, Adeniyi J O and Oladipo O 2004 Variability of foF 2 in the equatorial ionosphere; $A d v$. Space Res. 34 1901-1906.

Chaitanya P P, Patra A K and Rao V B 2012 Contrasting features of the F3 layer during high and low solar activity conditions observed from Indian low latitude; Indian J. Radio Space Phys. 41 121-129.

Chou Y T and Lee C C 2008 Ionospheric variability at Taiwan low latitude station: Comparison between observations and IRI 2001 model; Adv. Space Res. 42 673-681.

Dabas R S, Singh L, Lakshimi D R, Subramanyam P, Chopra P and Garg S C 2003 Evolution and dynamics of equatorial plasma bubbles: Relationship to $\mathrm{E} \times \mathrm{B}$ drift, post-sunset total electron content enhancements, and EEJ strength; Radio Sci. 38 1075, doi: 10.1029/2001RS002586.

Fejer B G 1997 The electrodynamics of the low latitude ionosphere recent results and future challenges; J. Atmos. Sol. Terr. Phys. 59 1465-1482.

Fejer B G and Scherliess L 1997 Empirical models of stormtime equatorial zonal electric fields; J. Geophys. Res. 102 24,047-24,056.

Fejer B G, de Paula E R, Heelis R A and Hanson W B 1995 Global equatorial ionosphere vertical plasma drifts measured by the AE-E Satellite; J. Geophys. Res. 100 5769-5776.
Forbes J M 1981 The equatorial electrojet; Rev. Geophys. Space Phys. 19(3) 469-504.

Gordienko G I, Aushev V M, Fedulina I N, Shi Ryazapova S and Shepherd M G 2005 Observation of the F2-layer variability from the 'Alma-Ata' observatory; J. Atmos. Sol. Terr. Phys. 67(6) 563-580.

Hanson W B and Moffett R J 1966 Ionization transport effects in the equatorial F region; J. Geophys. Res. 71 5559-5572.

Hines C O, Paghis I, Hartz T R and Fejer J A (eds) 1965 Physics of the Earth's Upper Atmosphere; Prentice-Hall, Inc. Englewood Cliffs, N.J.

Iheonu E E and Oyekola O S 2006 Vertical drift velocity in the daytime F-region at Ibadan estimated from ionosonde data; Indian J. Radio Space Phys. 35(1) 9-13.

Jin S G, Luo R J and Park P 2008 GPS observations of the ionospheric F2-layer behaviour during the 20th November 2003 geomagnetic storm over South Korea; J. Geodesy 82 883-892.

Kouris S S and Fotiadis D N 2002 Ionospheric variability: A comparative statistical study; Adv. Space Res. 29(6) 977-985.

Lilensten J and Blelly P L 2002 The TEC and F2 parameters as traces of the ionosphere and thermosphere; J. Atmos. Sol. Terr. Phys. 64 775-793.

Liu L, Yang J, Le H, Chen Y, Wan W and Lee C-C 2012 Comparative study of the equatorial ionosphere over Jicamarca during recent two solar minima; J. Geophys. Res. 117 A01315, doi: 10.1029/2011JA017215.

Mikhailov A V and Leschinskaya T Yu 1991 On the mechanism of daytime F2-layer negative disturbances at the geomagnetic equator; Geomag. Aeronom. 31 1027-1031.

Obrou O K, Bilitza D, Adeniyi J O and Radicella S M 2003 Equatorial F2-layer peak height and correlation with vertical ion drift and M(3000)F2; Adv. Space Res. 31(3) 513-520.

Oladipo O A, Adeniyi J O and Radicella S M 2009 Electron density distribution at fixed heights $\mathrm{N}(\mathrm{h})$ : Gaussian distribution test; J. Atmos. Sol. Terr. Phys. 71 1-10.

Oladipo O A, Adeniyi J O, Radicella S M and Obrou O K 2008 Variability of equatorial ionospheric electron density at fixed heights below the F2 peak; J. Atmos. Sol. Terr. Phys. 70 1056-1065.

Olawepo A O and Adeniyi J O 2012 Ionosphere's F2-layer response to 2006 geomagnetic storm at Ilorin, Nigeria; The African Rev. Phys. 7(0031) 277-281.

Oyinloye J O 1988 Equatorial HF radio wave absorption measurements and IRI; Atmos. Terr. Phys 50519.

Radicella S M and Adeniyi J O 1999 Equatorial ionospheric electron density below the F2 peak; Radio Sci. 34(5) 1153-1163.

Rajaram G and Rastogi R G 1977 Equatorial electron densities - Seasonal and solar cycle changes; J. Atmos. Terr. Phys. 39 1175-1182.

Risbeth $\mathrm{H}$ and Mendillo M 2001 Pattern of F2-layer variability; J. Atmos. Sol. Terr. Phys. 63(15) 1661-1680.

Risbeth H 1971 Polarization fields produced by winds in the equatorial F-region; Planet Space Sci. 19 357-369.

Sumod S G, Pant T K and Nayar S R P 2012 On the variability of the observed HF Doppler derived equatorial F-region plasma drifts during evening and morning hours and the chemical corrections therein; Indian J. Radio Space Phys. 41 130-140.

Scherliess L and Fejer B G 1999 Radar and satellite global equatorial F-region vertical drift model; J. Geophys. Res. 104 6829-6842. 
Uemoto J, Maruyama T, Saito S, Ishii M and Yushimura R 2010 Relationship between pre-sunset electrojet strength, PRE and ESF onset; Ann. Geophys. 28 449-454.

Woodman R F, Chau J L and Ilma R R 2006 Comparison of ionosonde and incoherent scatter drift measurements at magnetic equator; Geophys. Res. Lett. 33 L01103, doi: 10.1029/2005GL023692.
Zhang S R and Holt J M 2008 Ionospheric climatology and variability from long-term and multiple incoherent scatter radar observations: Variability; Ann. Geophys. 26 15251537.

Zhang M I, Shi J K, Wang X and Radicella S M 2004 Ionospheric variability at low latitude station: Hainan, China; Adv. Space Res. 34(9) 1860-1868.

MS received 3 September 2013; revised 27 November 2013; accepted 5 January 2014 